http://dx.doi.org/10.30681/23588403v12i03156175

\title{
GÊNEROS TEXTUAIS/DISCURSIVOS E ENSINO: A MÍDIA RADIOBLOG NA ESCOLA ${ }^{1}$
}

\author{
Emilio Davi SAMPAIO (UEMS) ${ }^{2}$ \\ Ilka Flores Rego e SILVA (UEMS) ${ }^{3}$ \\ Data de recebimento: 11/09/2019 \\ Aceite: 16/11/2019
}

\begin{abstract}
Resumo: Este trabalho apresenta aspectos conceituais relativos à teoria dos gêneros textuais/discursivos dentro de uma linha de pensamento bakthiniana, com atenção voltada aos pressupostos sociointeracionistas. Desde a publicação dos PCN (1998) e mais atualmente a BNCC (2017) nota-se que o ensino da língua materna no Brasil tem se encaminhado para um trabalho pautado nos gêneros discursivos/textuais. Sabe-se que os gêneros circulam socialmente, são instrumentos de comunicação e podem ser tomados como objetos de ensino. Com isso, objetiva-se discutir, neste texto, a importância efetiva de se inserir no ensino da Língua Portuguesa os gêneros textuais/discursivos, considerando as práticas de linguagem socialmente instituídas. Para fundamentar nossas proposições e discussão apoiamo-nos, entre outros, nos seguintes autores: Bakthin (1992); Dolz e Schneuwly (2011); Marcuschi (2009); Barbosa e Rovai (2012). Para corroborar nossa proposição, apresentamos, ao final, considerações a respeito do ensino de gêneros textuais midiáticos por meio do suporte radioblog na escola.
\end{abstract}

Palavras-chave: Gêneros textuais. Leitura. Ensino. Mídia.

Abstract: This paper presents conceptual aspects related to the theory of textual / discursive genres within a Bakthinian line of thought, focusing on socio-interactionist assumptions. Since the publication of the PCN (1998) and more recently the BNCC (2017) it is noted that the teaching of the mother language in Brazil has been directed to a work based on discursive / textual genres. It is known that genres circulate socially, are communication tools and can be taken as teaching objects. Thus, this paper aims to discuss the effective importance of inserting in the Portuguese language teaching the textual / discursive genres, considering the socially instituted language practices. To support our propositions and discusion rely, among others, on the following authors: Bakthin (1992); Dolz and Schneuwly (2011); Marcuschi (2009); Barbosa and Rovai (2012). To corroborate our proposition, we present, at the end, considerations about the teaching of textual media genres through radioblog support at school.

Keywords: Textual genres. Reading. Teaching. Media.

\section{Considerações iniciais}

\footnotetext{
${ }^{1}$ Este artigo é um recorte da Dissertação de Mestrado intitulada "Gêneros Jornalísticos: produção oral e escrita na escola”, oriunda de pesquisa interventiva do Mestrado Profissional em Letras (PROFLETRAS) Rede Nacional.

${ }^{2}$ Doutor em Letras pela UFRGS; Universidade Estadual de Mato Grosso do Sul; Dourados (MS); Brasil; emilio@uems.br

${ }^{3}$ Mestre em Letras pela UEMS-PROFLETRAS; Rede Pública de Ensino do MS; Antônio João (MS); Brasil; ilka.flores@hotmail.com
} 


\section{Revista de Estudos Acadêmicos de Letras}

O ensino de uma língua e o aprimoramento deste para seus falantes justifica-se pela necessidade de ampliar a capacidade comunicativa e a capacidade de adequar a língua a diversas situações de comunicação. Conforme Travaglia (2009), fazer essa adequação implica outras duas competências: a gramatical ou linguística e a textual.

Um ponto de partida no ensino de Língua Portuguesa é o de considerar que este será proposto a sujeitos que usam a língua, com uma gramática e um vocabulário próprio, daí o desafio, ao professor, de mostrar as várias possibilidades de uso da língua e o de criar mecanismos para dominar a língua falada e escrita, e para compreender que existem situações de comunicação que exigem diferentes graus de formalidade.

Segundo Cagliari (2010, p. 24):

O objetivo mais geral do ensino de Português para todas as séries da escola é mostrar como funciona a linguagem humana e, de modo particular, o português, quais os usos que tem e como os alunos devem fazer para estenderem o máximo, ou abrangendo metas específicas, esses usos nas modalidades escrita e oral, em diferentes situações de vida.

A função da escola é formar cidadãos participativos, e para que isso se realize, ela deve se basear num ensino para o letramento, através de práticas de linguagem que se aproximem das formas autênticas, para que os alunos se apropriem e possam atuar quando forem confrontados em diferentes situações sociocomunicativas. Ler, escrever, falar e ouvir são habilidades básicas da linguagem, e para desenvolvê-las cabe à escola organizar atividades para este fim, de forma que possibilite ao aluno essa condição. Sobre este assunto, de acordo com os PCN (1998, p. 32-33), a escola deve levar o aluno a:

- utilizar a linguagem na escuta e produção de textos orais e na leitura e produção de textos escritos de modo a atender a múltiplas demandas sociais, responder a diferentes propósitos comunicativos e expressivos, e considerar as diferentes condições de produção do discurso;

- utilizar a linguagem para estruturar a experiência e explicar a realidade, operando sobre as representações construídas em várias áreas do conhecimento: sabendo como proceder para ter acesso, compreender e fazer uso de informações contidas nos textos, reconstruindo o modo pelo qual se organizam em sistemas coerentes; sendo capaz de operar sobre o conteúdo representacional dos textos, identificando aspectos relevantes, organizando notas, elaborando roteiros, resumos, índices, esquemas etc.; aumentando e aprofundando seus esquemas cognitivos pela ampliação do léxico e de suas respectivas redes semânticas;

- analisar criticamente os diferentes discursos, inclusive o próprio, desenvolvendo a capacidade de avaliação dos textos: contrapondo sua interpretação da realidade a diferentes opiniões; inferindo as possíveis intenções do autor marcadas no texto; identificando referências intertextuais presentes no texto; percebendo os processos de convencimento utilizados para atuar sobre o interlocutor/leitor; identificando e repensando juízos de valor tanto socioideológicos (preconceituosos ou não) quanto 


\section{Revista de Estudos Acadêmicos de Letras}

histórico culturais (inclusive estéticos) associados à linguagem e à língua; reafirmando sua identidade pessoal e social;

- conhecer e valorizar as diferentes variedades do Português, procurando combater o preconceito linguístico;

- reconhecer e valorizar a linguagem de seu grupo social como instrumento adequado e eficiente na comunicação cotidiana, na elaboração artística e mesmo nas interações com pessoas de outros grupos sociais que se expressem por meio de outras variedades; - usar os conhecimentos adquiridos por meio da prática de análise linguística para expandir sua capacidade de monitoração das possibilidades de uso da linguagem, ampliando a capacidade de análise crítica.

Cabe ressaltar a importância da prática do professor de Língua Portuguesa na proposição de ensino significativo para uma efetiva compreensão da realidade, com metodologias coerentes aos propósitos do ensino da língua, que contribuam para o sucesso dos alunos no desenvolvimento das habilidades de leitura, escrita e comunicação oral.

Não parece difícil, entretanto carece de uma reflexão, uma mudança de postura e de visão quanto para quê, o quê e como ensinar. Percebemos que pelas orientações nas esferas institucionais, por indicações de estudiosos do ensino da língua materna e por propostas metodológicas baseadas na prática de leitura e produção textual, que já houve mudanças. Sobre a questão do trabalho com o texto em sala de aula, Bagno (2009, p. 66) assinala o seguinte:

O texto é que tem que ser o ponto de partida para qualquer estudo da linguagem humana em ação, em interação. Os estudos gramaticais tradicionais, no entanto, não levam isso em conta e tudo o que conseguem fazer é analisar a frase, a oração ou, quando muito, o período composto por mais de uma oração. Com isso, todo um mundo de coisas interessantes, fascinantes e importantes para o entendimento da linguagem humana se perde, não é estudado, fica oculto.

Observamos também que, na concepção enunciativo-discursiva da linguagem, proposta nos PCN e na BNCC de Língua Portuguesa, há a sugestão de que os gêneros do discurso sejam tomados como objeto de ensino-aprendizagem, numa proposta de articular práticas que desenvolvam a leitura, a escrita, a produção de texto escrito ou oral e a análise linguística.

Dentro dessa perspectiva, e levando em consideração ao que estipula a BNCC (2017) sobre o ensino dos gêneros textuais, associado às novas práticas sociais de linguagem, acreditamos que um trabalho escolar que desenvolva nos alunos habilidades e crie competências relacionadas às mídias sociais, como a radioblog, por exemplo, pode levá-los a uma aprendizagem bastante significativa em relação ao que circula no meio social. Portanto, certamente, cabe à escola organizar o trabalho com os gêneros textuais/discursivos que circulam na esfera pública, dentro do campo jornalístico/midiático. Sobre estas temáticas expostas vamos nos reportar adiante. 


\section{Revista de Estudos Acadêmicos de Letras}

\section{Leitura, escrita e oralidade}

O pleno exercício da cidadania requer a autonomia de agir e pensar, assim sendo, contribuir para desenvolver essas capacidades é um dos principais objetivos do ensino de Língua Portuguesa. Ao sujeito da ação de ensinar, o professor, cabe planejar a construção desses conhecimentos nas interações em sala de aula. O professor deve criar possibilidades de transposição desses saberes, visando potencializar a aprendizagem por meio da organização de diversas atividades a serem realizadas e compreendidas pelos alunos, enfatizando situações didáticas que promovam a interação deles com momentos em que haja tanto o registro escrito quanto a expressão oral.

Intervir na realidade se faz pelo domínio da condição do sujeito, da forma de interpretar e se posicionar no mundo. Segundo Solé (1998, p.22), “a leitura é um processo de interação entre o leitor e o texto". Nessa visão interativa, entende-se que a leitura é o processo de compreensão da linguagem escrita, ao considerar tanto o texto em sua forma, como o leitor, e com seus conhecimentos prévios.

Portanto, a capacidade de compreender um texto envolve conhecimentos de mundo, de práticas sociais e linguísticas das expectativas do leitor, e com base nisso constroem-se novos conhecimentos. Marcuschi (2009, p. 229-230) afirma que "compreender bem um texto não é uma atividade natural, nem uma herança genética; nem uma ação individual isolada do meio e da sociedade em que se vive. Compreender exige habilidade, interação e trabalho", a qual depende da interação entre o leitor e o texto, e que consiste num exercício de interpretação de enunciados, numa atividade colaborativa.

Conforme os PCN (2001), nas orientações para a prática da leitura, o trabalho tem como finalidade a formação de leitores competentes, não no sentido de profissionais, mas capazes de escrever com eficácia. Em relação a essas atividades, leitura e escrita, há de considerá-las práticas complementares no processo de letramento, na construção de conhecimentos a partir dos diferentes gêneros, ao ler e escrever, conforme as situações do uso da língua.

A respeito de leitura, os PCN preconizam que "uma prática intensa de leitura na escola é, sobretudo, necessária, porque ler ensina a ler e a escrever”, e quanto à prática de produção de textos trazem que "O trabalho com a produção de textos tem como finalidade formar escritores competentes capazes de produzir textos coerentes, coesos e eficazes" (BRASIL, 2001, p. 65). 
Assim, a prática de leitura e escrita não trata de metodologia nova, e não pode ser de desconhecimento dos professores, uma vez que o ensino de Língua Portuguesa tem estado no centro das discussões como uma necessidade de melhorar a qualidade de ensino.

Tanto o ensino da leitura quanto à produção oral e escrita tem a possibilidade de interagir nas diferentes situações sociais, e para isso o professor pode recorrer à teoria dos gêneros textuais (DOLZ; SCHNEUWLY, 2011). Esses estudiosos consideram a leitura de diferentes gêneros como uma estratégia propícia para compreender os usos da linguagem em diferentes contextos. Nesse sentido, a formação de um cidadão crítico e participativo se faz tanto pelo ensino da leitura quanto pela produção oral e escrita, ao interagir nas diversas situações sociais.

Nessa perspectiva, um dos objetivos da escola é a formação para a participação social, portanto, essas propostas de produção não podem manter-se apenas na esfera escolar, mas devem se projetar para fora dela, nos diversos gêneros, com finalidades, interlocutores e espaços sociais diferentes.

A produção textual de gêneros orais, ditos "mais formais" tem procedimentos que ora são iguais aos textos escritos, ora diferentes, com formas específicas e estratégias que se caracterizam de maneira própria. Para este trabalho, de forma planejada, o professor deve organizar e selecionar os gêneros.

Matta (2009, p. 66-67) propõe seguir diferentes direções para o aluno desenvolver a oralidade:

a) O oral pelo oral

- contar histórias, inventando-as ou reproduzindo-as;

- relatar acontecimentos de coisas que ocorrem na vida de cada um;

- debater, discutir, defender pontos de vista, emitir opiniões sobre temas variados;

- dar depoimentos.

b) Do oral para o escrito

- fazer e dar entrevistas;

- dar avisos;

- fazer convites;

- listas (de compras a fazer, de assuntos estudados);

- conclusões de debates.

c) Do escrito para o oral

- fazer convites;

- dar avisos;

- expor programações;

- apresentar resumos (inclusive de matérias de outras disciplinas);

- seminários sobre assuntos estudados.

Como podemos observar, o autor apresenta possibilidades de exercitar e ampliar a competência linguístico-comunicativa dos alunos, ao apresentar as diferenças nas modalidades faladas e escritas. Entender como se constrói o sentido de um texto é papel de todos os 
educadores. Com esse novo olhar para o texto, na concepção de linguagem como interação social e dialógica, o indivíduo atua nessa relação da linguagem na utilização da língua oral ou escrita, dentro de uma situação comunicativa. Conforme Matta (2009, p. 46):

\begin{abstract}
Interação verbal, então, na atitude de um professor de língua, deve ser a possibilidade de seu aluno estar em contato intermitente com a leitura e produção de textos, fazendo desse contato uma atitude viva dento do espaço escolar, como se ele existisse principalmente para isso e não como prática esporádica, envolvida em "mistérios", daquilo que é "difícil" e por isso mesmo refletido em uma aura de complexidade. Aliás, ler e escrever devem ser as práticas comuns, cotidianas, na escola como um todo, em todas as disciplinas. No nosso ver, a verdadeira interdisciplinaridade está aí, pois tudo é linguagem e tudo pode ser lido e escrito.
\end{abstract}

$\mathrm{O}$ ato de escrever pressupõe elementos e características, percebidos e adquiridos pela leitura, o qual amplia e favorece essa competência, pela adequação discursiva dos alunos. Nessa visão dialógica, tanto a fala como a escrita, constituem-se em um fenômeno interativo e dinâmico. Segundo Matta (2009, p. 52):

É muito interessante, nessa visão, a inclusão dos gêneros textuais e de seus usos no cotidiano de uma sociedade. Dessa forma, a fala e a escrita não podem ser colocadas em oposição, como dicotomias estanques, mas em relação entre si, como fato linguístico e prática social. Ademais, deve-se ter em conta que tanto a fala como a escrita podem variar, serem mais ou menos cuidadas em relação à norma-padrão, podem ser mais ou menos informais, já que ambas servem à interação verbal, sob a forma de diferentes gêneros discursivos, utilizando a variedade dialetal e o registro adequado ao contexto de uso.

Assim, cabe ao professor propor situações em que o aluno possa desenvolver práticas sociais, na leitura e produção de textos, orais e escritos. Nessa abordagem de ensino da língua materna, cumpre ressaltar a importância no uso efetivo da linguagem, numa perspectiva funcional.

\title{
1.1 Gêneros textuais/discursivos, ensino e sequência didática
}

Na perspectiva dos gêneros discursivos apresentados pelos PCN (2001) para o ensino de Língua Portuguesa, norteada pela teoria e concepção bakhtiniana dos estudos da linguagem e do ensino da língua, os quais privilegiam o texto e o envolvimento dos indivíduos em relação à sua produção, nas diversas atividades humanas, tem-se como intuito demonstrar as contribuições para um trabalho efetivo, com propostas possíveis de produção, circulação e 
recepção dos textos. Dessa forma, as atividades com textos na escola, na constituição da linguagem como ação social e nas noções de gêneros discursivos, contribuem como suporte didático ao professor de língua materna. Para Bakhtin, (1992, p. 279):

A utilização da língua efetua-se em forma de enunciados (orais e escritos), concertos e únicos, que emanam dos integrantes duma ou doutra esfera da atividade humana. $\mathrm{O}$ enunciado reflete as condições específicas e as finalidades de cada uma das esferas, não só por seu conteúdo (temático) e

por seu estilo verbal, ou seja, pela seleção operada nos recursos da língua - recursos lexicais, fraseológicos e gramaticais - mas também, e sobretudo, por sua construção composicional. Esses três elementos (conteúdo temático, estilo e construção composicional) fundem-se indissoluvelmente no todo do enunciado, e todos eles são marcados pela especificidade de uma esfera de comunicação. Qualquer enunciado considerado isolado é, claro, individual, mas cada esfera de utilização da língua elabora tipos relativamente estáveis de enunciados, sendo isso que denominamos de gênero do discurso.

Os Parâmetros Curriculares Nacionais retomam alguns conceitos de Bakhtin no que se refere aos gêneros textuais, e pontuam considerações importantes para o ensino da língua materna na perspectiva dos gêneros. Observa-se que os elementos basilares para aprendizagem, derivados da concepção de linguagem e língua, estão assim definidos:

Linguagem (...) como ação interindividual orientada por uma finalidade específica, um processo de interlocução que se realiza nas práticas sociais existentes nos diferentes grupos de uma sociedade, nos distintos momentos da sua história. Os homens interagem pela linguagem tanto em uma conversa e bar, entre amigos, ou ao redigir uma carta pessoal, quanto ao redigir uma crônica, uma novela, um poema, um relatório profissional (p.6). (...) enquanto atividade social e histórica, por meio dela, de geração em geração, se constroem quadros de referência culturais - representações, "teorias" populares e mitos, concepções e orientações ideológicas, inclusive preconceitos - por que interpretamos a realidade e as expressões linguísticas.

Língua é um sistema de signos específico, histórico e social, que possibilita ao homem significar o mundo e a sociedade. Assim, aprendê-la é aprender não somente as palavras e saber combiná-las em expressões complexas, mas aprender pragmaticamente os seus significados e, com eles, os modos pelos quais as pessoas entendem e interpretam a realidade e a si mesmas. (BRASIL, 2001 p. 23-24).

Encontra-se, também, sobre o discurso:

Produzir linguagem significa produzir discursos: dizer alguma coisa a alguém, de uma determinada forma, em um determinado contexto histórico e em determinada forma, em um determinado contexto histórico e em determinadas circunstâncias de interlocução. Isso significa que as escolhas feitas ao produzir um discurso não são aleatórias - ainda que possam ser inconscientes -, mas decorrentes das condições em que o discurso é realizado.(...) Isso tudo determina as escolhas do gêneros no qual o discursivo se realizará, dos procedimentos de estruturação e da seleção dos recursos linguísticos . (...) O discurso, quando produzindo manifesta-se linguisticamente por meio de textos (BRASIL/MEC/SEB, 2001, p. 25). 
Desta forma, entendemos que a manifestação da linguagem nas atividades humanas se dá por meio de textos, que é a materialização do discurso. Nessa mesma linha de raciocínio, conforme Passarelli (2012, p.121), “discurso é a propriedade de um sujeito se manifestar linguisticamente conforme a conveniência de determinada circunstância. Assim, o texto será o resultado, o produto concreto da atividade do discurso, visto que o discurso se concretiza no texto".

Barbosa; Rovai (2012, p. 09) sintetizam as razões para que os gêneros sejam tomados como um dos objetos de ensino-aprendizagem:

\footnotetext{
- os gêneros do discurso permitem capturar, para além de aspectos estruturais presentes em um texto, também aspectos sócio-históricos e culturais, cuja consciência é fundamental para favorecer os processos de compreensão e produção de textos;

- os gêneros do discurso nos permitem concretizar um pouco mais a que forma dizer em circulação social estamos nos referindo, permitindo que o aluno tenha parâmetros mais claros para compreender ou produzir textos, além de possibilitar que o professor possa ter critérios mais claros para intervir eficazmente no processo de compreensão e produção de seus alunos;

- os gêneros do discurso (e seus possíveis agrupamentos) fornecem-nos instrumentos para pensarmos mais detalhadamente as sequências e simultaneidades curriculares nas práticas de uso da linguagem (compreensão e produção de textos orais e escritos).
}

Entende-se que os gêneros discursivos/textuais são instrumentos de comunicação, existem das interações entre os sujeitos, nas diversas atividades do cotidiano, em certas necessidades e contextos e na escola como objeto de ensino-aprendizagem, e colaboram para uma postura mais reflexiva em relação ao uso da língua, na adequação e situação de produção.

Os PCN (BRASIL, 2001), ao tratarem de como "Aprender e Ensinar Língua Portuguesa" na escola, consideram o ensino e a aprendizagem de Língua Portuguesa resultantes da articulação de três variáveis: o aluno, os conhecimentos com os quais se opera nas práticas de linguagem e a mediação do professor. Sendo assim, o primeiro elemento, o aluno, é o sujeito da ação de aprender, aquele que age sobre o objeto do conhecimento; o segundo elemento, o objeto do conhecimento e o terceiro é a prática educacional do professor e da escola que organiza a mediação entre sujeito e objeto do conhecimento.

No sentido da mediação, é importante criar condições para que o aluno possa desenvolver a competência discursiva, ser capaz de utilizar a língua de modo variado, para produzir diferentes efeitos de sentido e adequar o texto a diferentes situações de interlocução oral e escrita no meio social em que atua.

Outro propósito a ser observado com relação ao ensino é que em determinadas situações de aprendizagem é necessário destacar os gêneros que merecerão abordagem mais aprofundada, 


\title{
Revista de Estudos Acadêmicos de Letras
}

pois estes existem em número ilimitado. Entende-se que é de bom termo priorizar os textos que caracterizam os usos públicos da linguagem, sendo os mais utilizados numa sociedade letrada.

Levando em consideração a questão dos agrupamentos dos gêneros e progressão (DOLZ; SCHNEUWLY, 2004), é importante criar uma situação de ensino que ofereça condições para a escrita, a leitura e a produção de textos, orais e escritos, analisando a grande variedade de textos e suportes. Para isso, pode-se adotar como ferramenta o desenvolvimento de sequências didáticas ${ }^{4}$ (DOLZ; NOVERRAS; SCHNEUWLY, 2004) organizadas de forma gradual, em que os alunos possam progressivamente apropriarem-se das características discursivas e linguísticas dos gêneros estudados para produzir seus próprios textos, e fornecer instrumentos para superar os problemas apresentados.

Para a concretização destes princípios, são mencionados nos PCN, aspectos organizadores dos conteúdos do ensino de Língua Portuguesa e critérios para a sequenciação dos conteúdos, projetos e módulos didáticos. Nesta organização de conteúdos, estes estão separados em dois eixos de práticas de linguagem: as práticas de uso da linguagem e as práticas de reflexão sobre a língua e a linguagem. Conforme Rojo (2002, p. 35):

\begin{abstract}
Mais uma vez, aqui, as práticas de leitura/escuta de textos e produção de textos orais e escritos estariam integradas na abordagem do texto como unidade de ensino para a construção do gênero como objeto de ensino e as práticas de análise linguística ou de reflexão sobre a linguagem seriam resultantes destas e estariam também inteiradas nas práticas de uso da linguagem.
\end{abstract}

A organização de uma progressão de ensino tem como propósito preparar o aluno para dominar o uso da língua em diversas situações de comunicação. Depois de esclarecidas as finalidades deve-se proporcionar condições para que ele aprenda a comunicar-se, e pela concepção interacionista sociodiscursiva, priorizar o ensino do texto pelo seu funcionamento comunicativo. Na esteira do que foi exposto, assim se pronunciam Dolz; Schneuwly, (2011, p. 42):

- prepará-los para dominar a língua em situações variadas, fornecendo-lhes instrumentos eficazes;

- desenvolver nos alunos uma relação com o comportamento discursivo consciente e voluntária, favorecendo estratégias de autorregualação;

- ajudá-los a construir uma representação das atividades de escrita em situações complexas, como produto de um trabalho e de uma lenta elaboração.

\footnotetext{
4 “Uma 'sequência didática' é um conjunto de atividades escolares organizadas, de maneira sistemática, em torno
} de um gênero textual oral ou escrito" (DOLZ; NOVERRAS; SCHNEUWLY, 2004, p. 97) 
Assim sendo, consideramos importante assegurar a aprendizagem ao longo do processo, sendo necessário preparar estratégias para atingir as exigências curriculares, em etapas que proporcionem a aprendizagem de expressão comunicativa, para a formação de sujeitos autônomos, num processo sistemático de produção oral e escrita, com atividades propostas por sequências didáticas, organizadas em módulos, com a finalidade de melhorar determinada prática de linguagem, que são instrumentos de interação social.

As sequências didáticas buscam facilitar a apropriação dos gêneros textuais, pois no desenvolvimento das atividades surgem as dúvidas, apresentam-se as dificuldades e possíveis soluções, mediadas pelo professor, que fornece meios para o ensino da textualidade. Sobre as estratégias de ensino, Dolz; Schneuwly (2011, p. 45) explicam:

Finalmente, as estratégias de ensino supõem a busca de intervenções no meio escolar que favoreçam a mudança e a promoção dos alunos a uma melhor mestria dos gêneros e das situações de comunicação que lhes correspondem. Trata-se, fundamentalmente, de se fornecerem aos alunos os instrumentos necessários para progredir. Para fazê-lo, as atividades comunicativas complexas que os alunos ainda não estão aptos a realizar de maneira autônoma serão, de certa maneira, decompostas, o que permitirá abordar um a um, separadamente, os componentes que colocam problemas para eles. As intervenções sociais, a ação recíproca dos membros do grupo e, em particular, as intervenções formalizadas nas instituições escolares são fundamentais para a organização das aprendizagens em geral e para o processo de apropriação e gêneros em particular. Nesse sentido, as sequências didáticas são instrumentos que podem guiar as intervenções dos professores.

Do ponto de vista teórico, sobre a diversidade textual, os autores tratam do agrupamento de gêneros como instrumento para construir a progressão, que são seleções dos gêneros a serem tratados na sequência didática, em vários ciclos de ensino, com objetivos de ensino propostos. Sobre o processo de seleção dos gêneros, Dolz; Schneuwly (2011, p. 50) consideram que é preciso que os agrupamentos:

1- Correspondam às grandes finalidades sociais legadas ao ensino, respondendo às necessidades de linguagem em expressão escrita e oral, em domínios essenciais da comunicação em nossa sociedade (inclusive na escola);

2- $\quad$ Retomem, de modo flexível, certas distinções tipológicas que já figuram em numerosos manuais e guias curriculares;

3- Sejam relativamente homogêneos quanto às capacidades de linguagem dominantes implicadas na mestria dos gêneros agrupados.

Sendo assim, ao propor uma metodologia, com enfoque na teoria dos gêneros textuais/discursivos, sugere-se um rompimento com o ensino tradicional da língua materna, 


\section{Revista de Estudos Acadêmicos de Letras}

com foco em normas e conceitos; dirige-se, portanto, para o funcionamento discursivo da língua, relacionado às formas e seu contexto de uso e condições de produção. O ensino da língua deve ser norteado por uma proposta de ensino de práticas de linguagem, com atividades de expressão oral e escrita, com organização de uma progressão temporal. Tendo como base no agrupamento de gêneros e por diferentes níveis de linguagem, adaptados às situações concretas de uso, num modelo de construção de conhecimento que organize as capacidades de linguagem, propícios a um melhor encaminhamento para a competência linguística.

\subsection{Gêneros orais}

Atualmente, apesar de algumas resistências, tem-se dado certa importância à expressão oral nos contextos sociocomunicativos e na função social que a escola desempenha, sobretudo na formação de um cidadão crítico, ético, livre e participativo, coconstrutor de uma sociedade mais justa, em consenso com a Lei de Diretrizes e Bases (LDB), a BNCC e os Parâmetros Curriculares Nacionais.

Sobre a articulação do ensino-aprendizagem de forma integrada, tanto os PCN quanto a BNCC propõem o ensino sob quatro eixos norteadores: oralidade, leitura, produção, análise e reflexão da língua, de forma que privilegie a oralidade, quanto a competência ligada a contextos formais da fala, em diferentes situações de comunicação e em variados suportes. Em especial, no ensino de Língua Portuguesa, é preciso considerar essas várias práticas sociais, para que se proponha situações de ensino aos alunos que os aproximem de práticas autênticas e os conduza ao letramento necessário para o desenvolvimento de suas potencialidades comunicativas.

Consoante ao que foi exposto anteriormente, os PCN trazem o seguinte:

Nas inúmeras situações sociais do exercício da cidadania que se colocam fora dos muros da escola - a busca de serviços, as tarefas profissionais, os encontros institucionalizados, a defesa de seus direitos e opiniões - os alunos serão avaliados (em outros termos, aceitos ou discriminados) à medida que forem capazes de responder a diferentes exigências de fala e de adequação características próprias de diferentes gêneros do oral. (BRASIL, 1998, p. 25)

Garantir espaços para o ensino-aprendizagem dessas práticas comunicativas, onde o estudante possa estar livre para conhecer, pensar e criar, é fundamental para promover o letramento. Ser letrado é ser capaz de atuar nos meios sociais, a seu favor e a favor da sociedade, isto é, ser competente no uso da língua nas diversas situações comunicativas, nas oportunidades 


\section{Revista de Estudos Acadêmicos de Letras}

pessoais e nas possibilidades de transformações sociais nas mais variadas esferas das atividades humanas.

A linguagem acontece em situações reais, com propósitos definidos e se materializa em textos escritos e orais, com habilidades linguísticas de falar, escutar, ler e escrever. Os professores, na função de mediadores, cumprem o seu papel quando desenvolvem o ensino de forma integrada, pois o conhecimento fragmentado não contribui na formação de um sujeito capaz de exercer a sua cidadania.

Nem sempre é possível separar um tipo de linguagem de outra, nesse caso, os textos escritos e orais, pois os textos orais formais ancoram-se em textos escritos, exigem um planejamento conforme o evento, isto é, uma linguagem adequada ao ato de comunicação. $\mathrm{Na}$ escola, dá-se maior atenção à produção de textos escritos, enquanto que os orais sempre ficam em segundo plano ou, na maioria das vezes, são relegados completamente pelos professores.

A respeito dessa situação, Dolz; Schneuwly (2011, p. 125) expõem que: "embora a linguagem oral esteja bastante presente nas salas de aula (nas rotinas cotidianas, na leitura de instruções, na correção de exercícios etc.) afirma-se frequentemente que ela não é ensinada, a não ser incidentalmente, durante atividades diversas e pouco controladas". Ainda, sobre esse aspecto, Schneuwly (2011, p. 112-113), observa o seguinte:

Dada a idealização da escrita como forma perfeita da língua - e, logo, da expressão da realidade e do pensamento -, a fala só pode ser concebida de duas formas, aliás, não mutuamente exclusivas: seja como tendente necessariamente à forma ideal, representada precisamente pela escrita, fundindo oral e escrita numa unidade mítica de uma língua ideal; seja como fundamentalmente diferente da escrita em sua forma e em sua função, já que ela é o lugar da expressão espontânea cotidiana que, por definição, não tem cidadania no sistema escolar.

Nessa mesma perspectiva, Marcuschi (2009) considera, numa leitura dos PCN de língua portuguesa, que há uma relativa variedade de gêneros a serem ensinados, tanto os orais quanto os escritos, porém os gêneros orais, em geral, ainda não são tratados de modo sistemático. $\mathrm{O}$ autor afirma que há uma confusão entre oralidade e escrita. Pois não há clareza quanto a critérios que teriam sido usados para estabelecer essas distinções, e ainda deixa claro que há mais gêneros sugeridos na escrita do que na fala, e também, muito mais gêneros para a atividade de compreensão do que para a produção.

Assim, ao professor cumpre a tarefa de ampliar as situações de abordagem teóricometodológica e criar situações que possibilitem o ensino da produção textual oral, de forma a 
contextualizar, nos diversos conhecimentos, os conteúdos, as habilidades e as competências, não deixando de considerar as experiências do educando.

O ensino do texto na escola induz à dicotomia escrita/oral, pela denominação e pelo programa curricular, e acaba por considerar a oralidade como um gênero mais informal, mais cotidiano, menos planejado, isto é, espontâneo e livre, não sendo passível de objeto de ensino, porém, o ensino que necessita de intervenção, é o ensino dos gêneros orais formais públicos. Como explica Schneuwly (2011, p. 112):

O oral que se aprende é o oral da escrita; aquele que prepara a escrita, pois permite encontrar ideias, elaborar uma primeira formulação; aquele que por meio das correspondências grafofonêmicas, permite passar o código escrito; finalmente e principalmente, aquele que não é senão a oralização de um escrito.

O aspecto central nesta questão é a impossibilidade de situar a oralidade e a escrita em sistemas linguísticos diversos, de modo que ambas fazem parte do mesmo sistema de língua. Quanto à produção de textos orais, nos Parâmetros Curriculares Nacionais, espera-se que o aluno:

Planeje a fala pública usando a linguagem escrita em função da situação e dos objetivos estabelecidos; considere os papéis assumidos pelos participantes, ajustando o texto à variedade linguística adequada; saiba utilizar e valorizar o repertório linguístico de sua comunidade na produção de textos; monitore seu desempenho oral, levando em conta a intenção comunicativa e a reação dos interlocutores e reformulando o planejamento prévio, quando necessário; considere possíveis efeitos de sentido produzidos pela utilização de elementos não-verbais. (BRASIL, 1998, p. 51)

O gênero textual oral, como conteúdo escolar, exige uma ação pedagógica que garanta, em sala de aula, atividades sistemáticas, planejadas com situações de aprendizagem significativas sobre os usos e formas da língua oral, adequados a diferentes situações comunicativas, assim:

O trabalho com linguagem oral deve acontecer no interior de atividades significativas: seminários, dramatização de textos teatrais, simulação de programas de rádio e televisão, de discursos políticos e de outros usos públicos da língua oral. Só em atividades desse tipo é possível dar sentido e função ao trabalho com aspectos como entonação, dicção, gestos e postura que, no caso da linguagem oral, têm papel complementar para conferir sentido aos textos. (BRASIL, 2001, p. 51-52)

Em consonância, vê-se que as escolas privilegiam a produção de textos escritos, e prevalece o ensino da leitura e escrita em detrimento ao da escuta e dos gêneros orais. 


\section{Revista de Estudos Acadêmicos de Letras}

Entretanto, é reconhecida a importância do ensino dos gêneros orais, necessário na formação do aluno para a vida em sociedade, para agir como cidadão atuante. É visto que os parâmetros Curriculares Nacionais sugerem três práticas: a de leitura de textos, da produção de textos e a análise linguística, em sala de aula. Tais práticas devem estar interligadas na unidade textual, na leitura e na produção intelectual do estudante, como pressupostos da relação de ensino para a construção de situações comunicativas, materializado num texto oral ou escrito.

A reflexão proposta ancora-se na compreensão de que as atividades discursivas socialmente instituídas fazem parte de um controle social e na necessidade de interlocução humana, pois o conhecimento e o domínio dos gêneros legitimam o discurso, criam oportunidades e proporcionam a possibilidade de participação social, no exercício da cidadania. Diante disso, exigem-se novas práticas pedagógicas que incluam a oralidade no ensino, ora limitada, porém não se pode dizer que ela não faça parte do discurso, e não há motivo para isolar uma linguagem da outra, pois estão interligadas e são socialmente instituídas.

Os gêneros são produtos da cultura de dada sociedade como modelos comunicativos, utilizados em determinadas situações, com conteúdo, forma e estilo (BAKHTIN, 1992). Significa que dominar essas produções, orais e escritas, é aprender a língua. Desenvolver gêneros mais complexos implica em subsidiar condições para a construção de novas capacidades de linguagem, numa situação de produção e aproximação dos mesmos na sua forma autêntica à realidade de sua circulação. Importante também é a escolha dos gêneros a serem trabalhados na progressão do conteúdo, com base no nível curricular, e a observância nos agrupamentos dos gêneros, os quais podem relacionar e transferir os conhecimentos já adquiridos (SCHNEUWLY; DOLZ, 2011).

Os PCN, sobre linguagem e participação social, pontuam o seguinte:

O domínio da língua tem estreita relação com a possibilidade de plena participação social, pois é por meio dela que o homem se comunica, tem acesso à informação, expressa e defende ponto de vista, partilha ou constrói visões de mundo, produz conhecimento. Assim, um projeto educativo comprometido com a democratização social e cultural atribui à escola a função e responsabilidade de garantir a todos os seus alunos o acesso a saberes linguísticos necessários para o exercício da cidadania, direito inalienável de todos. (BRASIL, 2001, p. 23)

Portanto, a escola deve assegurar ao aluno a ampliação de seus conhecimentos, progressivamente, não deixando de lado a sua relação com as novas práticas sociais surgidas com o aparecimento da tecnologia e da era digital. Somente desse modo a escola vai possibilitar ao aluno que ele assuma a palavra e se posicione como sujeito consciente, nas mais variadas 


\section{Revista de Estudos Acadêmicos de Letras}

situações de uso e de comunicação, conferindo assim, o domínio do gênero oral, assim como o escrito, condição do pleno exercício da cidadania.

\subsection{Gêneros textuais/discursivos, ensino e a radioblog}

Conforme mencionado, é função da escola promover a formação de um cidadão crítico, ético, livre e participativo, e coconstrutor de uma sociedade mais justa, estes princípios estão em conformidade com a Lei de Diretrizes e Bases da Educação, tendo os PCN e a BNCC como consenso principal. Para isso, é preciso construir meios para que se desenvolva essa postura, por práticas que garantam essa autonomia, com propostas de ensino de Língua Portuguesa que possibilitem uma aprendizagem suficiente, aliando-se, assim, as ações e as interações sociais ao uso da linguagem nas suas múltiplas funções.

Aprender a ler novos signos, que surgem principalmente com a tecnologia, é assegurar a identidade e a liberdade de cada um. Esse novo contexto possibilita modos de ler diferentes, e de reconhecer a linguagem, esta, cada vez mais diversificada, de forma mais ampla. Sendo assim, acreditamos que a escola não deve deixar de acompanhar esses avanços, que é uma realidade, para possibilitar aos educandos o domínio das linguagens diversas.

Com o uso das novas tecnologias surgem novos gêneros, com o desenvolvimento dos sistemas de informação e comunicação, é preciso considerar os multiletramentos nas práticas letradas, que usam diferentes mídias de comunicação, em diferentes linguagens.

Ao aproveitar o potencial de interações nos ambientes virtuais, as ferramentas, as publicações em blogs de textos, a produção de material, edição e revisão dos conteúdos têm mais sentido. Dentro do contexto escolar, nesse trabalho com múltiplas linguagens, por exemplo, a atividade de gravar vídeos ou arquivos de áudio possibilita aos alunos uma ação protagonista, pois nesse processo eles planejam, produzem e fazem a edição, mediados pelo professor.

Os currículos de Língua Portuguesa apontam outros gêneros e linguagens. Nessa perspectiva Barbosa; Rovai (2012, p.11) atestam:

Como uma das marcas identitárias de grupos sociais, o uso das diferentes linguagens ao mesmo tempo constitui e manifesta a diversidade cultural, sendo também marcado pela explicitação das contradições sociais e culturais expressas por contraposições entre o padrão e as variações, o culturalmente valorizado e o "marginal", o hegemônico e o contra-hegemônico, o tradicional e a ruptura ou vanguarda. Seja no uso de uma língua, que sempre contará com o fenômeno da variação linguística, seja no interior de uma dada forma de manifestação artística, essas oposições estão 
presentes e sua exploração deve constituir-se em um dos objetivos de aprendizagem, dado seu valor político, social e cultural. Mais do que contemplar essas diferenças, é preciso considerar efetivamente as manifestações linguísticas e culturais dos alunos e propor diálogos (por vezes, conflituosos) com as demais formas de manifestações culturais, na perspectiva de promover uma ampliação no universo cultural dos alunos que não seja impositiva ou que reafirme as relações de dominações existentes e que acabem por afastar o aluno da escola.

A partir dessa realidade, das mudanças de interesses dos sujeitos e da sociedade, com as novas práticas sociais de comunicação, na leitura e escrita, por meio das novas tecnologias, cabe a escola propor atividades para capacitar os alunos a interagirem com os gêneros digitais. Em sala de aula, é importante buscar práticas escritas e orais usadas na sociedade, aumentando, desta forma, a competência linguística na diversidade de textos orais e escritos, que circulam no meio social. Sendo, então, a escola o lugar de ampliar esses conhecimentos, ao aproximar os alunos desses gêneros digitais, que podem fazer parte de seu cotidiano, como leitores e possíveis autores.

Com atenção ao ensino de língua portuguesa associado à tecnologia e aos multiletramentos é possível considerarmos a construção de uma programação de rádio (radioblog) na escola, esta com o objetivo de promover a cidadania e o protagonismo dos alunos. Para isso, devemos levar em conta o fato de como os jovens se relacionam com essa mídia, a partir de seus conhecimentos prévios, o que possibilita serem agentes sociais protagonistas na construção de práticas concretas e de conhecimentos outros na área de língua portuguesa.

Não se pode dispensar que a escola deve buscar entender a relação dos jovens com as novas mídias, como produtores e consumidores dessas culturas locais e globais e proporcionar práticas letradas e criativas. Nessa dimensão situacional, divulgar e compartilhar informações é uma forma de contribuir e determinar a interação dos participantes.

Para que esta proposta educacional se concretize é necessário criar documentos em áudio (podcasts) para serem publicados na radioblog da escola. As radioblogs têm temáticas variadas numa versão de áudio, conforme explica Barbosa; Rovai (2012, p. 26) sobre o formato podcast:

Podcasts são arquivos de áudio distribuídos pela web em que os internautas disponibilizam seleções de músicas, entrevistas e notícias e falam sobre diversos assuntos (como em um blog). Para criar um podcast, é preciso ter uma ferramenta de edição de áudio. Uma opção gratuita é o Audacity. 


\title{
Revista de Estudos Acadêmicos de Letras
}

A proposta de produção de um programa de rádio possibilita a elaboração de pautas, com quadros informativos, musicais, esportivos e culturais. Oportuniza delimitar o enunciado pela intenção e situação de produção, e considerar a finalidade e expressão do que se fala e para quem fala, assumindo assim, variadas formas de organização dos discursos e diferentes linguagens, conforme os sentidos que o falante elabora, como atrair seu público.

Assim, Moura; Gribl (2012, p. 242), sobre os aspectos da teoria de Bakhtin a respeito do caráter híbrido e intercalado do gênero podcasts para radioblog, expressam o seguinte:

\begin{abstract}
A começar pela natureza híbrida, verificada pela união de dois meios de comunicação, o rádio e o blog, podemos considerar que o gênero podcast para radioblog carrega e transforma algumas características próprias do rádio (vistas, principalmente, pela materialidade das gravações/transmissões em áudio, seus conteúdos e organização que lhe são próprios), assim como reconfigura o funcionamento de um blog (visto como ambiente virtual com certa frequência de atualizações de seus conteúdos (posts), que podem ser acessados de maneira assíncrona - independentemente da linha temporal da transmissão/emissão). Assim, a radioblog pode ser visto em seu caráter híbrido, não apenas como rádio ou como blog, mas como soma ou como intersecção do que ocorre separadamente, ao verificarmos a periodicidade de atualizações de seus conteúdos em um formato em áudio que pode ser reproduzido em diferentes momentos (e não apenas ao vivo, como em emissões radiofônicas) e em diferentes espaços de circulação (conectado à internet ou em aparelhos reprodutores de MP3iPod e similares - se o ouvinte desejar "baixar" ou "assinar" (feed) os arquivos para ouvir em outros lugares e momentos, sem conexão com a internet).
\end{abstract}

Com isso, acreditamos que ao considerar a produção de uma programação de radioblog, há o desenvolvimento de diferentes capacidades dos alunos, nas variedades de interação por meio da língua oral e escrita, pelo contato com os instrumentos midiáticos, pelo engajamento social, quando na realização dessas atividades. É uma ferramenta que permite o contato direto com a linguagem pela interação a partir de situações comunicativas significativas, ao utilizar, por exemplo, três gêneros textuais jornalísticos: a notícia, a entrevista e a reportagem, a serem produzidos no contexto escolar, com o objetivo particular de desenvolver produções realizadas nesse meio jornalístico, propiciando o engajamento social dos alunos.

Dessa forma, produzir para aprender, adaptar seus conhecimentos, suas produções aos auditórios escolares e extraescolares, significa vislumbrar um projeto educativo mais amplo, que propicia o exercício da cidadania. Divulgar suas produções para fora da esfera escolar, com a exibição de sua programação, transmitidas pela web, de cunho educativo e comunicativo, com essa aproximação de fato às produções autênticas de uso social, permite ao aluno trabalhar com fatos reais, numa situação compartilhada, sendo um instrumento que exige um fazer pedagógico mais elaborado, mais dedicado. E, com a utilização das tecnologias de comunicação, a possibilidade de aprendizagem com articulação entre o oral e a escrita, nas diferentes 


\section{Revista de Estudos Acadêmicos de Letras}

linguagens, certamente contribuirá para melhorar a escrita, com o apoio dos registros mais formais.

Nesse novo contexto de comunicação, o das mídias digitais, proliferam novos gêneros do discurso no mundo virtual. A escola deve considerar esse meio de interação com grande potencial, o qual acelera a evolução do ensino dos gêneros, pelo meio tecnológico e pelo modo de produção, pois interferem na natureza dos gêneros, nas relações interpessoais e na forma de relação com a linguagem.

Em certas modalidades, os gêneros sofrem mudanças, variações produzidas no contexto da mídia virtual, principalmente no uso da escrita, com interações com sujeitos reais, mas com relação virtual, uma prática social de comunicação, uma nova situação de letramento cultural, a qual evidencia o modo de circulação dos textos orais e escritos pelo suporte radioblog. Marcuschi (2009, p.174), a respeito do suporte discorre o seguinte:

Definição de Suporte: entendemos aqui como suporte de um gênero um locus físico ou virtual com formato específico que serve de base ou ambiente de fixação de gênero materializado como texto. Pode-se dizer que suporte de um gênero é uma superfície física em formato específico que suporta, fixa e mostra um texto. Essa ideia comporta três aspectos:

a) suporte é um lugar (físico ou virtual)

b) suporte tem formato específico

c) suporte serve para fixar e mostrar o texto.

Apostar no caráter educativo da radioblog é reconhecer que trabalhar com gêneros textuais envolve o uso de novas tecnologias de comunicação e de informação, com o intuito de ampliar os discursos, através do estudo dos gêneros, mídias e linguagens variadas para a apropriação do conhecimento. Além disso, aprende-se também como produzir programas radiofônicos, como analisar o radiojornalismo na relação com outras mídias, a importância da organização verbal, a elaboração de roteiros para entrevistas e reportagens, aspectos estes que servem para o desenvolvimento da competência comunicativa dos alunos, principalmente aos aspectos da oralidade.

\section{Referências}

BAGNO, Marcos. Nada na língua é por acaso: por uma pedagogia de variação linguística. São Paulo: Parábola Editorial, 2009.

BAKHTIN, Mikhail. Estética da criação verbal. São Paulo: Martins Fontes, 1992. 
BARBOSA, Jackeline Peixoto e ROVAI, Célia Fagundes. Gêneros do discurso na escola: rediscutindo princípios e práticas. 1 ed. São Paulo. FTD. 2012.

BRASIL. Parâmetros Curriculares Nacionais. Ensino Fundamental. Volume 2. Secretaria de Educação Fundamental. Brasília: MEC/SEF, 2001.

BRASIL. Parâmetros curriculares nacionais: Terceiro e quarto ciclos do ensino fundamental: língua portuguesa/Secretaria de Educação Fundamental. Brasília: MEC/SEF, 1998.

BRASIL. Ministério da Educação. Base Nacional Comum Curricular- BNCC $2^{\mathbf{a}}$ versão. Brasília, DF, 2017.

CAGLIARI, Luiz Carlos. Alfabetização e linguística. 1. ed. São Paulo: Scipione, 2010.

DOLZ, Joaquim; SCHNEUWLY, Bernard. Gêneros e progressão em expressão oral e escrita elementos para reflexões sobre uma experiência suíça (francófona). In: ROJO, Roxane; CORDEIRO, Glaís Sales (Trad. e Org.) Gêneros Orais e Escritos na Escola. Campinas, Mercado das Letras, 2011.

DOLZ, Joaquim; NOVERRAZ, Michèle; SCHNEUWLY, Bernard. Sequências didáticas para o oral e a escrita: apresentação de um procedimento. In: ROJO, Roxane; CORDEIRO, Glaís Sales (Trad. e Org.). Gêneros Orais e Escritos na Escola. Campinas, Mercado das Letras, 2004.

MARCUSCHI, Luiz Antônio. Produção Textual, Análise de Gêneros e Compreensão. São Paulo: Parábola Editorial, 2009.

MATO GROSSO DO SUL, Referencial Curricular da Rede Estadual de Ensino MS. SED/MS, 2012.

MATTA, Rozângela Schemim da. Português: Linguagem e Interação. Curitiba: Bolsa Nacional do Livro LTDA, 2009.

MOURA, Eduardo, GRIBL, Heitor. Radioblog - Vozes e espaços de atuação cultural. Multiletramentos na escola. In: ROJO, Roxane; MOURA, Eduardo (Orgs.). São Paulo: Parábola Editorial, 2012.

PASSARELLI, Lílian Ghiuro. Ensino e correção na produção textos escolares. 1. Ed.- São Paulo: Telos, 2012.

ROJO, Roxane. Os PCNs, as práticas de linguagem (dentro e fora da sala de aula) e a formaçãode professores - Uma apresentação. In: ROJO, Roxane (Org). A prática de linguagem em sala de aula: Praticando os PCNs. Campinas: Mercado das Letras, 2002. 
SCHNEUWLY, Bernard. Palavras e Ficcionalização: Um caminho para o ensino da Linguagem

Oral. Gêneros Orais e Escritos na Escola. In: ROJO, Roxane; CORDEIRO, Glais Sales (Trad. e Org.) Campinas, SP: Mercado das Letras, 2011.

SOLÉ, Isabel. Estratégias de leitura. 6. ed. - Porto Alegre: Artmed, 1998.

TRAVAGLIA, Luiz Carlos. Gramática e Interação: uma proposta para o ensino de gramática. 14. ed. - São Paulo: Cortez, 2009. 